\title{
Zur Analyse der Nucleinsäuren.
}

\author{
Von
}

H. Steudel.

(Aus dem physiologischen Institut in Heidelberg.)

(Der Redaktion zugegangen am 3. Mai 1907.)

Vor einiger Zeit ${ }^{1}$ ) habe ich das Baryumsalz einer neuen Säure von der Formel $\mathrm{C}_{6} \mathrm{H}_{10} \mathrm{O}_{8}$ beschrieben, die man durch Oxydation der Nucleinsäure mit Salpetersäure erhält und die augenscheinlich aus der Kohlehydratgruppe der Nucleinsäure stammt. Bei der weiteren Untersuchung wurde gefunden, daß diese Säure, die ich unpräjudizierlich «Epizuckersäure» nenne, besonders mit organischen Basen gut krystallisierende Salze liefert. So ist z. B. das saure Chininsalz ein in langen Nadeln krystallisierender Körper, der relativ schwer in Wasser löslich ist.

$0,1480 \mathrm{~g}$ verloren bei $100^{\circ} 0,0102 \mathrm{~g}$ und sättigten, nach Kjeldahl verbrannt, $4,9 \mathrm{ccm} \mathrm{n} / 10-0 x a l s a ̈ u r e=6,89 \% \quad \mathrm{H}_{8} \mathrm{O}$ und $4,64 \% \mathrm{~N}$.

Berechnet für:

$\mathrm{C}_{20} \mathrm{H}_{24} \mathrm{~N}_{8} \mathrm{O}_{2} \cdot \mathrm{C}_{6} \mathrm{H}_{10} \mathrm{O}_{8}+2 \mathrm{H}_{8} \mathrm{O}: 6,32 \% \mathrm{H}_{8} \mathrm{O}$ und $4,92 \% \mathrm{~N}$.

Eine ausführliche Mitteilung wird demnächst in dieser Zeitschrift erscheinen.

1) Diese Zeitschrift, Bd. L, S. 538. 